\title{
Lei Maria da Penha: as representações do judiciário sobre a violência contra as mulheres
}

\author{
The Maria da Penha Law: representations of the \\ judiciary concerning violence against women
}

\author{
Madge PORTO' \\ Francisco Pereira COSTA ${ }^{1,2}$
}

\begin{abstract}
Resumo
Este estudo teve como objetivo identificar as representações de juízes sobre a violência contra as mulheres, de forma a compreender como tais representações pessoais podem ou não influenciar as decisões prolatadas em suas sentenças. Foi realizada a análise de conteúdo de 15 sentenças, proferidas entre setembro de 2006 e agosto de 2007, correspondente ao primeiro ano de vigência da Lei 11.340/2006, conhecida como Lei Maria da Penha, em uma cidade da região Norte do Brasil. Nesse contexto, pode-se afirmar que os magistrados percebem a violência contra as mulheres como elemento constitutivo das relações entre gêneros, como um fato que não oferece perigo para elas e que não se enquadra no estatuto jurídico, não configurando crime. Há uma naturalização do lugar social definido para as mulheres pela sociedade patriarcal e a consequente invisibilidade das várias formas de violência por elas sofrida, o que dificulta o acesso à Justiça.
\end{abstract}

Unitermos: Poder judiciário. Representações. Violência contra as mulheres.

\begin{abstract}
The aim of the presentstudy was to identify the representations ofjudges regarding violence against women in order to understand how these personal representations may or may not influence the decisions handed down when sentencing. An analysis was conducted of the content of 15 sentences handed down in a city in northern Brazil between September 2006 and August 2007 - the first year of Law 11.340/2006, known as the Maria da Penha Law. In this context, it may be stated that magistrates perceive violence against women as a component element in the relationship between men and women - as a fact that does not pose a danger to women and which is not covered by the legal statute and thereby does not constitute a crime. There is an acclimation of the social standing defined for women by the patriarchal society and the consequent invisibility of the different forms of violence women suffer, which hinders their access to justice.
\end{abstract}

Uniterms: Judicial power. Representations. Violence against women.

Este artigo tem como objetivo identificar as representações de juízes de Direito sobre as muIheres em situação de violência, e sobre o contexto de violência contra elas. A análise de con- teúdo de seus discursos foi feita a partir de sentenças prolatadas no primeiro ano de vigência da Lei 11.340/2006, conhecida como Lei Maria da Penha (Brasil, 2006).

1 Universidade Federal do Acre, Grupo de Pesquisa Direito, Sociedade e Meio Ambiente. R. Álvaro Rocha, 101, Conjunto Universitário 1, Qd. 45, c.10, Distrito Industrial, 69915-300, Rio Branco, AC, Brasil. Correspondência para/Correspondence to: M. PORTO. E-mail: <madgeporto@gmail.com>.

2 Universidade Federal do Acre, Curso de Direito. Rio Branco, AC, Brasil. 
Entende-se ser importante a análise desse novo estatuto jurídico para descobrir como os operadores do direito o estão aplicando. Também é necessário entender até que ponto a nova legislação é eficiente para o enfrentamento da violência contra as mulheres e para a promoção dos direitos humanos das mesmas. Pretende-se compreender como os magistrados percebem o universo da violência contra as mulheres e como suas concepções pessoais podem ou não influenciar suas decisões, em detrimento da referência legal. Isso porque outros estudos (Anchieta \& Galinkin, 2005; Cruz, 2002; Oliveira \& Amâncio, 2006; Porto, 2006; Streck, 2002) apontam que há um componente subjetivo presente nas ações dos sujeitos humanos, mesmo que estes se proponham a ser objetivos e imparciais.

As crenças e os valores pessoais e subjetivos não podem ser desconsiderados quando se pretende pensar sobre as ações humanas e sobre suas representações (Porto, 2006). Assim, entender quais as crenças e valores que estão dando sustentação às decisões dos magistrados, e como eles determinam ou não seus julgamentos, pode trazer informações quanto à possibilidade de acesso das mulheres em situação de violência à sua plena cidadania. Em outras palavras, quanto mais o magistrado se afastar de suas crenças e limitar-se aos dispositivos da Lei Maria da Penha, mais as muIheres terão oportunidade de acessar os direitos previstos pela lei. Enquanto os magistrados tiverem como referência suas próprias crenças - construídas numa sociedade patriarcal em que os papéis de homens e mulheres distinguem-se a partir de diferenças de acesso ao poder (Saffioti, 2004) -, as mulheres correm o risco de ter seus direitos, agora expressos na lei, desconsiderados e pensados a partir de representações patriarcais.

É preciso considerar que, ao longo da construção histórica de direitos, os movimentos feministas travaram uma luta intensa pela conquista dos direitos das mulheres, denominando-os de direitos humanos das mulheres (Barsted \& Hermann, 2001a). Elaboraram um discurso sobre os direitos humanos com um olhar de equidade de gênero, preconizando que os direitos só serão direitos humanos quando incluírem as questões feministas.

As representações dos magistrados que serão investigadas, a partir da produção escrita destes, têm como pressuposto teórico a noção de representações sociais de Porto (2006), que se baseia no mesmo conceito elaborado por Serge Moscovici:

\begin{abstract}
... possibilidade de compreensão do fenômeno da violência contemporânea, assumindo ser impossível compreender esse fenômeno sem se interrogar sobre os sentidos, os valores e as crenças que estruturam e presidem a vida social, os quais são o conteúdo por excelência das representações sociais (Porto, 2006, p.250).
\end{abstract}

\section{A violência contra as mulheres}

A partir da década de 1950, as mulheres passaram a questionar sobre a naturalização da opressão e da discriminação de que eram vítimas. Assim, tem início uma série de reflexões, movimentos, produções literárias e ações de resistência, como a marcha da panela vazia, a participação na luta pela anistia e pela redemocratização do País, a criação de grupos feministas para discutir sobre literatura relacionada às mulheres ou sobre a sexualidade (Pinto, 2003).

A condição social das mulheres, como fruto de uma construção histórica do patriarcalismo e do capitalismo, já vinha sendo questionada desde o começo do século XX com o movimento das sufragistas (Pinto, 2003). Na metade do século, com a discussão teórica de Simone de Beauvoir em O segundo sexo, inicia-se uma reflexão teórica sobre as questões específicas das mulheres (Beauvoir, 1967).

Na década de 1980, Joan Scott diferencia sexo de gênero, "O gênero é um elemento constitutivo de relações sociais fundadas sobre as diferenças percebidas entre os sexos, e o gênero é um primeiro modo de dar significado às relações de poder" (Scott, 1990, p.14). A partir dessa nova categoria de análise, foram se desenvolvendo estudos sobre as mulheres e o fenômeno da violência em sua vida.

Assim, no contexto das sociedades patriarcais, a violência doméstica, também referida como violência familiar, é considerada um tema de difícil abordagem, pois questiona a instituição familiar. A discussão do tema traz à tona um aspecto delicado, pois acontece no espaço privado, um espaço reservado, que precisa ser resguardado do público. A exposição do que lá ocorre causa desconforto, uma vez que o que era idealizado, o espaço 'sagrado do lar', passa a ser questionado, tornando-se objeto de investigação - policial ou científica. Essas idealizações, frutos de uma construção cultural, 
vão desde o lar como um lugar seguro, livre de conflitos, até as idealizações do papel de cada membro da família burguesa (Costa, 1989).

A violência doméstica contra as mulheres pode ser definida como aquela ação de dominação infligida à mulher pelo homem com o qual tem ligações afetivas e que objetiva mantê-la sob jugo (Sabadell, 2005; Silva, 1999). É uma forma de violência, muitas vezes, sutil e de difícil constatação. Também difícil é a percepção da gravidade de suas consequências. Nesse caso, o agressor é alguém com quem a mulher tem alguma ligação afetiva: parceiro, pai, padrasto ou outro familiar. Os parceiros ou ex-parceiros frequentemente são os agressores principais que aparecem nas denúncias registradas nas delegacias da mulher (Brandão, 1998; Diniz, Silveira \& Mirim, 2006; d'Oliveira \& Schraiber, 2000; Giffin, 1994; Venturi, Recamán \& Oliveira, 2004).

Da violência derivam sofrimentos permanentes e crônicos, com um aumento na demanda por serviços de saúde. As mulheres procuram esses serviços tentando buscar uma solução para o sofrimento e para outras consequências decorrentes da violência sistemática (Schraiber, d'Oliveira, Strake \& Liberman, s.n.; d'Oliveira \& Schraiber, 2000). Isso porque a busca pelos serviços de saúde é motivada pelas consequências da violência, mesmo que não haja a consciência de que se está vivendo nesse estado. Numa menor magnitude, essas mulheres também buscam as instâncias do Poder Judiciário, o que pressupõe uma decisão consciente de responsabilização do agressor, para uma possível mediação dos conflitos conjugais ou familiares (Brandão, 1998).

Existe uma gradação da violência, das formas mais sutis até os aspectos mais cruéis, o que, dependendo do grau de tolerância social, pode ser aceito ou reprimido. Uma forma de violência ainda aceita socialmente é sua utilização como instrumento educativo, ou seja, como forma de punir, com vista ao enquadramento nas regras sociais (Portella, 2000).

As mulheres sentem dificuldade em revelar a situação de violência vivida. Primeiro, por ser um problema desagradável, incômodo e vexatório, o que dificulta a lembrança e a exposição aos outros, que nada podem fazer, dado que é uma questão da vida privada. Segundo, por existirem poucos espaços para o acolhimento dessas experiências. E, por fim, ainda há a percepção de que existe algum tipo de merecimento quando alguém sofre violência, ou seja, que a vítima estaria sendo punida por não ter cumprido alguma obrigação, o que a faz sentir-se culpada (Portela, 2000). Tudo isso gera uma desqualificação do problema por parte das usuárias do Sistema Único de Saúde (SUS), e que se estende para toda a equipe de saúde (Schraiber et al., s.n.), para a polícia (Brandão, 1998) e para o Judiciário (Streck, 2002). Assim, as mulheres, além da violência que sofrem dentro de casa, quando buscam apoio institucional, acabam, muitas vezes, sentindo que não há solução para seus problemas. Dessa forma, sentem-se, mais uma vez, destituídas de seus direitos de cidadãs.

A partir do entendimento da violência doméstica contra as mulheres como fruto de uma construção social e histórica de um lugar de subordinação, é importante investigar as representações de juízes de Direito a partir de seus valores e crenças sobre as mulheres e sobre as situações de violência contra elas. Isso porque terão que julgar as situações de violência segundo a Lei Maria da Penha, que define como formas de violência doméstica e familiar em seu Art. 70:

I - a violência física, entendida como qualquer conduta que ofenda sua integridade ou saúde corporal;

II - a violência psicológica, entendida como qualquer conduta que the cause dano emocional e diminuição da autoestima ou que Ihe prejudique e perturbe o pleno desenvolvimento ou que vise degradar ou controlar suas ações, comportamentos, crenças e decisões, mediante ameaça, constrangimento, humilhação, manipulação, isolamento, vigilância constante, perseguição contumaz, insulto, chantagem, ridicularização, exploração e limitação do direito de ir e vir ou qualquer outro meio que Ihe cause prejuízo à saúde psicológica e à autodeterminação;

III - a violência sexual, entendida como qualquer conduta que a constranja a presenciar, a manter ou a participar de relação sexual não desejada, mediante intimidação, ameaça, coação ou uso da força; que a induza a comercializar ou a utilizar, de qualquer modo, a sua sexualidade, que a impeça de usar qualquer método contraceptivo ou que a force ao matrimônio, à gravidez, ao aborto ou à prostituição, mediante coação, chantagem, suborno ou manipulação; ou que limite ou anule o exercício de seus direitos sexuais e reprodutivos; 
IV - a violência patrimonial, entendida como qualquer conduta que configure retenção, subtração, destruição parcial ou total de seus objetos, instrumentos de trabalho, documentos pessoais, bens, valores e direitos ou recursos econômicos, incluindo os destinados a satisfazer suas necessidades;

$V$ - a violência moral, entendida como qualquer conduta que configure calúnia, difamação ou injúria (Brasil, 2006 p.17).

Diante da nova na legislação, é necessário também que mudanças sejam incorporadas pelos profissionais do Poder Judiciário. Assim, estes precisariam refletir, em algum momento, sobre suas crenças, opiniões e vivências, sobre as relações entre mulheres e homens e a violência nesse contexto.

\section{Método}

Este estudo foi realizado numa cidade da região Norte do Brasil, com pouco mais de 300mil habitantes. O objetivo foi realizar um estudo exploratório, descritivo e qualitativo, a partir de uma pesquisa documental. Para tal, foram coletados 15 processos dos 1945 enquadrados na Lei 11.340/06, no período de setembro de 2006 a agosto de 2007.

Foram selecionados os processos em que já havia sido proferida a sentença de mérito, ou seja, que apresentavam a decisão final do juiz, condenando ou absolvendo o réu. Esses processos estavam distribuídos nas varas criminais com competência para julgar os casos de violência contra as mulheres, já que o Judiciário da cidade, à época da coleta, não tinha implantado o Juizado de Violência Doméstica e Familiar contra a Mulher (Brasil, 2006).

Para este artigo, as sentenças foram analisadas de forma a identificar as representações sobre dois temas: o contexto da situação de violência e a violência contra as mulheres. Utilizou-se o método da análise de conteúdo (Bardin, 1977; Nascimento-Schulze \& Camargo, 2000), em que a unidade de registro foi o tema. Foram dois os temas escolhidos, a partir do conceito de gênero (Scott, 1990) e das produções científicas e políticas do movimento feminista, anteriormente apresentadas.

Assim, foram definidas duas categorias temáticas: o contexto da situação de violência e a violência contra as mulheres. A primeira categoria refere-se às representações sobre o contexto em que ocorrem as situações de violência, o cenário e os atores da situação, além do sentido (significado) que é atribuído a um episódio de violência em que existe um homem agressor, uma mulher vítima e, entre eles, um vínculo afetivo, fruto de relação familiar ou conjugal. A segunda categoria refere-se especificamente ao sentido que é dado à violência contra a mulher, pois o ponto principal da lei é coibir a violência doméstica e familiar contra a mulher (Brasil, 2006).

O estudo apresenta limites, pois não se pode assegurar que só esses 15 processos foram sentenciados no período especificado para o estudo, devido à forma de organização dos arquivos do Poder Judiciário (vários lugares para a guarda dos processos e a possibilidade de estes serem retirados da instituição pelos advogados das partes). Dessa forma, o número reduzido de sentenças não permite uma análise de frequência, ou seja, uma análise também quantitativa. Assim, as análises são exclusivamente qualitativas e buscam compreender quais os valores e crenças dos juízes que julgam a partir da Lei Maria da Penha, nesse contexto.

Por fim, por se tratar de um estudo documental cujo objeto de análise - as sentenças de mérito - está acessível na internet, o projeto não foi encaminhado ao comitê de ética em pesquisa com seres humanos. Todavia, teve-se o cuidado de não se apresentar o nome da cidade onde o estudo foi realizado, de modo a resguardar de eventuais identificações os profissionais que produziram os documentos analisados.

\section{O que escrevem os magistrados em suas sentenças}

Antes de apresentar os resultados, é importante destacar alguns limites da análise. Os resultados encontrados precisam ser entendidos dentro do contexto de produção das sentenças judiciais, ou seja, segundo as características e normas de elaboração de documentos forenses. Há no Poder Judiciário uma retórica específica e a utilização de normas definidas de escrita, inclusive com frases prontas que se repetem nas sentenças (ver adiante as sentenças 7 e 8). De outro lado, no espaço dedicado à decisão do juiz, há a oportunidade de uma expressão mais livre, em que se podem identificar repre- 
sentações sobre alguns temas. Todavia, considera-se possível, na prática, serem as sentenças escritas por auxiliares e depois ratificadas ou retificadas pelo juiz, seja ele titular ou substituto. Dessa forma, não se tem como afirmar que as ideias apresentadas nas sentenças sobre a violência contra as mulheres são ideias, crenças, enfim, representações dos juízes titulares das varas. Contudo, pode-se afirmar que são representações do Poder Judiciário encontradas no contexto em que houve o julgamento.

\section{Resultados e Discussão}

Nos 15 processos analisados, existem 20 vítimas e 24 situações enquadradas como crimes, tanto de lesão corporal quanto de ameaça. Foram determinadas 15 absolvições, 8 condenações e observada 1 desistência. Nos processos estudados, há decisões proferidas por juízes dos dois gêneros, sendo uma delas prolatada por juiz substituto.

A leitura das sentenças proporcionou, a partir das duas categorias semânticas principais - o contexto da situação de violência e a violência contra as mulheres -, a definição das subcategorias: reconciliação, idealização da família, ambiguidade quanto à prova material do crime, negação da violência conjugal como crime, justificativa à agressão pelo uso de álcool/drogas, inconformismo/não aceitação da separação, proteção da mulher contra privações econômicas.

\section{O contexto da situação de violência}

Esta categoria se refere à forma como os juízes percebem/entendem o contexto da violência contra as mulheres, ou seja, como percebem a cena onde esse tipo de violência acontece. Agrupa quatro subcategorias: reconciliação, idealização da família, ambiguidade quanto à prova material do crime e negação da violência conjugal como crime.

\section{Reconciliação}

A reconciliação da vítima com o réu descaracteriza o crime, afastando a possibilidade de imputação de pena.
Nada obstante, não me parece que tenha havido efetivas ameaças capazes de impor qualquer temor na vítima, eis que ela própria declarou que já se reconciliou com o acusado, de modo que não tem intenção de vê-lo condenado, pois, de acordo com a declaração prestada em audiência, o réu teria mudado o seu comportamento e nunca mais voltou a agredi-la ou ameaçá-la (Sentença 7).

Reafirmando que não se pretende fazer uma análise da Ciência Jurídica e considerando que ela tem suas referências técnicas e teorias, pretende-se apresentar uma análise exclusivamente do ponto de vista das representações. Dessa forma, a identificação da existência da ameaça sai do ponto de vista da vítima - que recorreu à justiça porque se sentiu ameaçada - e instaura-se no ponto de vista do magistrado. Em outras palavras, o juiz é que faz a análise da existência ou não da ameaça, o que é sua função. Contudo, ele a fez utilizando outro fato, a reconciliação. Assim, devido à reconciliação, a ameaça, classificada no Código Penal como crime, não foi considerada. O interessante é perceber que esse deslocamento de entendimento é determinado por crenças sobre as mulheres, construídas no sistema patriarcal, como por exemplo, fragilidade, inconstância e dependência.

\section{Idealização da família}

... é uma lamentável desavença entre irmãos, na qual o melhor caminho a ser adotado é a absolvição do acusado para que não se fomente, ainda mais, a discórdia no seio familiar. Quem sabe se assim não se consegue de novo unir os dois irmãos (Sentença 1).

Nesse caso há a defesa de uma ideia contrária à definição de violência contra as mulheres determinada pela lei. Aqui o magistrado apoia-se na noção idealizada de família, desconsiderando que a Lei 11.340/2006 fora criada para dar conta desses episódios de violência ocorridos dentro do espaço privado. O objetivo da nova lei é fazer com que não mais se admita que, em nome da união familiar, as mulheres tenham minimizado o seu direito de viver uma vida sem violência.

Há, nesse caso, uma fala do senso comum que é utilizada como justificativa judicial, ou seja, há uma suposição de harmonia na relação familiar, a partir de uma compreensão superficial, desprovida de uma análise da situação, dos sujeitos envolvidos, e das 
consequências do fato para a mulher vítima. A harmonia dentro do lar custa o sentimento de injustiça da vítima e a reafirmação de seu lugar subalterno em relação aos homens.

\section{Ambiguidade quanto à prova material do crime}

Outra questão que se destaca é que, no contexto da violência contra as mulheres, a palavra do réu é tomada como verdade, em detrimento da palavra da vítima:

A autoria do crime de ameaça recai sobre a pessoa do acusado nos termos do depoimento da vítima, mas não restou comprovada estreme de dúvidas, haja vista que o réu, quando foi ouvido na instrução criminal em juízo, negou que tenha efetivamente ameaçado de morte a pessoa da vítima (Sentença 6).

A fundamentação está pautada na ausência de provas, não obstante as possibilidades de provar a violência caracterizada na Lei 11.340/2006 sejam limitadas (Porto, Santos \& Leite, 2008). Além disso, mesmo quando comprovada a materialidade do crime, há formas de minimizá-lo:

A materialidade está devidamente comprovada pelo Boletim de Ocorrência ..., pelo laudo de exame de corpo de delito ..., e pelo auto de prisão em flagrante ... . Em relação à suposta lesão corporal, a vítima esclareceu que tal ocorrera quando ambos tentavam puxar o filho que o acusado queria levar, vindo a vítima a cair no chão, ocasião em que o acusado a teria acertado com um chute na região da coxa, mas sem maior gravidade, tanto que nem houve uma efetiva lesão (Sentença 10).

Neste caso, o que foi comprovado pelos exames e reafirmado nas próprias palavras do juiz passa à categoria de suposição - uma suposta lesão, que é declarada como chute, com a vítima no chão, depois de ter caído com o bebê que segurava no colo. Ressalta-se que, nesse momento a fala da vítima passa a ser tomada como verdade, mesmo quando nega o laudo, que tem o estatuto de comprovação oficial da materialidade. Nesse ponto, cabe pensar o que determina a força dessa palavra contra as provas. Talvez seja a tentativa implícita dos magistrados de manterem a estrutura familiar, atenuando a ação do homem e apoiando a resignação da mulher. Quando fazem isso, em tese, resolvem o problema. Parece que, se a mulher minimiza a ação violenta, sua fala é acatada, ocorrendo o contrário quando faz uma acusação.

Outro ponto a ser refletido a partir dessa fala é o que seria uma "efetiva lesão". Seria o caso de fratura óssea ou perda de movimento? O exame de corpo de delito aponta a gravidade da lesão, quando esta existe. Assim, se houve a materialidade da lesão, é porque houve lesão. Dessa forma, como poderia ela ser tratada como suposição apenas porque a mulher minimizou o fato?

Essa atitude do magistrado demonstra o quanto ainda não há a percepção das características da violência doméstica contra as mulheres. Percebe-se por meio desses resultados que os magistrados não identificam a ambivalência das mulheres diante da situação de violência e diante do parceiro, nem as tentativas que elas fazem para resgatar a relação afetiva, nem mesmo o significado da violência para elas. Enfim, o magistrado pensa o universo das relações mediadas pela violência fora de seu contexto, a partir de uma referência pessoal, ou mesmo, de um modelo idealizado do que deveria ser a relação entre mulheres e homens.

\section{Negação da violência conjugal como crime}

Outro elemento que se destaca é que os magistrados, em alguns momentos, negam explicitamente a lei ora em discussão:

... a vítima ... demonstrou que não se sentiu ameaçada pelas palavras proferidas pelo seu companheiro, o que não caracteriza o crime tipificado ... De outra parte, compulsando os autos verifica-se que a "ameaça" teria sido proferida no meio de uma discussão familiar, onde o clima de exaltação reinava entre os contendores (réu e vítima). A ameaça proferida no calor do litígio conjugal não caracteriza crime, eis que não há seriedade na promessa do mal injusto, mormente quando o casal litigante encontrava-se com os ânimos exaltados ... (Sentença 10).

Percebe-se, na sentença acima, a negação do conceito de violência doméstica explicitado pela Lei Maria da Penha. Há uma problemática com características peculiares, da qual as leis existentes não davam conta e para a qual o novo estatuto jurídico apresenta encaminhamentos definidos. Assim, a ameaça que ocorre dentro de uma discussão familiar pode confi- 
gurar-se uma conduta delituosa, definida como violência psicológica (Brasil, 2006).

A literatura (Heise, Pitanguy \& Maciel 1994; Mirim, 2006) mostra que a violência contra as mulheres é sistêmica, repetitiva, que se inicia com ameaças e lesões leves, e tende a se agravar ao longo de um tempo. Há uma vulnerabilidade de gênero (Meneghel et al., 2003), ou seja, ser mulher é condição de vulnerabilidade às situações de violência. Assim, quando o juiz minimiza o ato praticado sem fazer nenhuma intervenção, o efeito do acesso ao Judiciário pode ser a banalização do ato praticado e do próprio sistema. Em outras palavras, uma efetiva desconsideração da lei, o que pode aumentar os números da violência contra a mulher.

Para o juiz que prolatou a sentença acima, a ameaça "proferida no calor do litígio conjugal" não caracteriza crime, sinalizando que casos semelhantes julgados por ele poderão receber o mesmo tratamento. A maioria dos crimes de violência contra as mulheres ocorre no âmbito privado, numa típica briga de casal, que muitas vezes se agrava até culminar em sequelas graves e homicídios de mulheres.

\section{A violência contra as mulheres}

Esta categoria se refere à forma como os juízes percebem/entendem a experiência de violência vivida pelas mulheres, ou seja, o que para eles significa e caracteriza esse tipo de violência. Foi dividida em três subcategorias: justificativa à agressão pelo uso de álcool/ drogas, inconformismo/não aceitação da separação por parte do homem agressor, proteção da mulher contra privações econômicas.

\section{Justificativa da agressão pelo uso deálcool/drogas}

Entre os magistrados, percebe-se o entendimento de que a violência contra as mulheres é justificável, dada a condição do agressor de usuário de substâncias que alteram a consciência, principalmente o álcool.

... nas condições em que se encontrava o acusado por ocasião dos fatos, ou seja, sob o efeito de álcool e de entorpecentes, o mesmo quando ameaçou sua genitora não poderia estar agindo com o dolo exigido para a configuração do delito de ameaça. Não estava o réu em seu estado normal. Não possuía por ocasião dos fatos ânimo calmo e refletido (Sentença 14).

No entendimento do magistrado, alguém alcoolizado não tem condições de discernimento, de modo que não havendo dolo não haveria crime. O réu, no caso, era um dependente químico que ameaçara a mãe e fora absolvido. Houve um entendimento de que o crime de ameaça não se concretizou por inexistência de dolo, ou seja, não foi uma ação praticada com a intenção livre e consciente de violar o direito alheio.

Nem a agressão à própria mãe mereceu uma intervenção. O Judiciário manteve-se inerte diante de alguém que bebe e, por beber, acredita poder agredir uma mulher. Aqui o magistrado poderia ter enquadrado o caso na Lei Maria da Penha, na tipificação de violência psicológica, de alguma forma demarcando que a ação de ameaçar uma mulher é crime.

O álcool é um fator precipitante da violência, mas não é a causa. O que causa essa violência é o entendimento de que as mulheres estão subordinadas aos desejos e caprichos dos homens (Diniz et al., 2006; Soares, 2005).

Outro ponto que se destaca aqui é que, mesmo diante de tal circunstância, não há a solicitação da intervenção por parte dos profissionais de saúde, ou seja, da equipe multiprofissional a que a lei se refere:

Art. 30. Compete à equipe de atendimento multidisciplinar, entre outras atribuições que Ihe forem reservadas pela legislação local, fornecer subsídios por escrito ao juiz, ao Ministério Público e à Defensoria Pública, mediante laudos ou verbalmente em audiência, e desenvolver trabalhos de orientação, encaminhamento, prevenção e outras medidas, voltados para a ofendida, o agressor e os familiares, com especial atenção às crianças e aos adolescentes (Brasil, 2006, p.27).

Parece haver, para os magistrados, o entendimento de que álcool e outras drogas eliminam o "dolo exigido para a configuração do delito de ameaça", independentemente da pessoa e da situação. Aqui se pode perguntar, não há culpados? Além do mais, parece ser aceitável "sair da linha" quando sob o efeito da bebida e isso passa a ser um álibi para os que agridem mulheres e até as matam. Diz o magistrado:

... entendo que no caso não se pode identificar o dolo específico exigido para a caracterização do 
delito de ameaça. A ameaça para restar caracterizada deve ser proferida seriamente e no caso, em face da embriaguez do acusado, ainda que voluntariamente, a ameaça não teve carga intimidativa (Sentença 15).

\section{Inconformismo/não aceitação da separação}

O dolo também não é considerado em outras situações, como a que se segue:

Por fim, o próprio representante do Ministério Público, órgão acusador, titular da ação penal, reconhece que não existem provas suficientes acerca da alegada ameaça e que a entrada do réu na residência da vítima não se revestiu de dolo específico de violar, mas parecendo um certo inconformismo pelo fim do relacionamento amoroso que houve entre ambos ou uma manifesta vontade de reatar a relação (Sentença 6).

Neste caso, a invasão foi justificada pelo juiz. No seu entendimento, a ação seria esperada e justificada, e a mulher que foi vítima teria que aceitar essa invasão porque o homem está inconformado e achava-se no direito de perturbá-la. Mais uma vez, percebe-se que a característica da violência contra a mulher, que demandou uma lei específica, não foi observada.

A ameaça, mesmo no contexto doméstico entre pessoas que têm vínculo afetivo, precisa ser contida, pois pode resultar em agressões cada vez mais perigosas. Percebe-se, assim, que continua vigente uma representação patriarcal, como Saffioti (2004) fundamenta em seu estudo.

\section{Proteção à mulher}

É interessante perceber a necessidade que o magistrado tem de, alguma forma, justificar sua decisão. Ao que parece, há uma percepção de que está julgando com base mais em suas convicções do que na lei, e por isso uma justificativa é importante:

... uma eventual condenação do réu por tal crime somente traria maiores transtornos para a família inteira, que seria novamente desagregada e passaria pelas maiores privações, notadamente de ordem econômica (Sentença 7).

Por outro lado, uma eventual condenação do réu por tal crime somente traria maiores transtornos para a família inteira, que seria novamente desagregada e passaria pelas maiores privações, notadamente de ordem econômica (Sentença 8).

Os grifos nas sentenças 7 e 8 demonstram que há uma ideia padronizada, principalmente relacionando a violência à questão socioeconômica. Essas transcrições das sentenças também revelam uma percepção de que os casos são "os mesmos". Destaca-se o argumento de que a mulher terá mais prejuízos se houver a justa condenação. Para o magistrado o enquadramento do ato nos limites da lei é desvantajoso para a mulher, devido a uma suposta condição de submissão econômica desta. E decidindo pela não condenação estaria protegendo a mulher de dificuldades mais graves.

\section{Discussão complementar}

Em vários casos, inclusive no caso de Maria da Penha, que deu nome à Lei 11.340/2006, há tentativa de homicídio - por vezes consumado - após as mulheres denunciarem ameaças classificadas como "sem consequência", que "não são sérias", ou que "não tem intenção de agredir". Alguns casos, inclusive apresentados na grande mídia nacional, por não terem nenhuma resposta efetiva dos poderes constituídos, terminaram em tragédias com a morte das mulheres.

Perante a Justiça, o sentimento do agressor, de supostamente querer reatar a relação, parece suficiente para retirar a existência de dolo, enquanto o sentimento de ameaça vivenciado pela mulher não serve para incriminá-lo. Para ela se exige a prova, para ele a especulação é suficiente. E mesmo entendendo que a lei brasileira considera uma pessoa inocente até que se prove o contrário e que, quando não se tem certeza absoluta da autoria do crime, a decisão é sempre favorável ao réu, em decorrência do princípio in dubio pro reo, há que se refletir na questão.

Mais difíceis de serem provados são os casos de agressão psicológica, que exigem pedido de investigação acerca de suas consequências. No entanto, não há solicitação de exames para comprovar a existência ou não de consequência desse tipo de agressão, como observaram Porto, Santos \& Leite (2008), de modo que não há como produzir prova material que sustente uma condenação em juízo.

É importante destacar que alguns estudos (Alves \& Coura-Filho, 2001; Mirim, 2006; Saffioti, 2004; Soares, 
2005) apontam a violência psicológica como grave e até mais marcante que as agressões físicas, pois as marcas ficam na alma. Dessa forma, minimizar atos como esses pode colaborar para a banalização da violência.

Ademais, se ambos já se reconciliaram, é porque o tom da suposta ameaça realmente não era sério e capaz de intimidar a vítima, não configurando, assim, o delito previsto no artigo 147, do Código Penal (Sentença 7).

Nada obstante, não me parece que tenha havido efetivas ameaças capazes de impor na vítima, eis que ela nem sequer tinha tomado a iniciativa de procurar a polícia, que ficava nas proximidades e a própria declarou que já se reconciliou com o acusado, de modo que não tem intenção de vê-lo condenado, pois, de acordo com a declaração prestada na audiência, o réu teria mudado o seu comportamento e nunca mais voltou a agredi-la ou ameaçá-la (Sentença 8).

Como foi apresentado anteriormente, a reconciliação é percebida pelo magistrado como suficiente para negar a ameaça. Este desconsidera a situação típica da mulher que sofre violência doméstica, discutida na literatura sob o conceito de ciclo da violência e tendo ainda o molde dos Juizados Especiais Criminais (JECRIM) como referência (Brasil, 2003; Debert \& Oliveira, 2007; Guimarães, Silva \& Maciel, 2007), ou seja, a reconciliação minimiza o ato de violência, em especial as ameaças. Os casos também são tratados como se fossem iguais, o que pode ser observado nas sentenças 7 e 8 (tópico 2.3), com trechos idênticos. Também se destaca, nesse contexto, que a desistência, que acontecia nas delegacias especializadas da mulher, mudou de local, mas continua acontecendo, agora no Judiciário, legitimada pela argumentação jurídica dos juízes (Alexy, 2005).

A desistência do processo e a retirada da queixa podem estar relacionadas à ausência de amparo à vítima por parte do poder público. Durante o período em que se desenrola o processo, estão presentes o sentimento de desamparo e o medo de não ter a quem recorrer, além da vergonha pela agressão, frente à banalização da violência.

Esses resultados revelam o quanto os magistrados ainda estão fazendo suas decisões baseadas em valores e crenças do senso comum, com influência da sociedade patriarcal. Além disso, percebe-se que a Lei Maria da Penha ainda não é a referência para os julga- mentos dos crimes contra as mulheres. Isso se dá, possivelmente, porque as representações precisam de mais tempo para ser mudadas e porque apenas a mudança da lei não é suficiente para mudar o entendimento, os valores e as crenças dos magistrados. Há de se ter uma alteração de valores e crenças que acompanham os pensamentos, para que a Lei Maria da Penha passe a ser utilizada dentro de novos referenciais e que, de fato, represente um novo paradigma para que mulheres e homens estabeleçam relações de respeito e igualdade.

\section{Considerações Finais}

As rápidas mudanças sociais impactam as várias esferas da vida social. Necessariamente, essas mudanças promovem transformações nos estatutos jurídicos que normatizam as novas formas de referência para a vida em sociedade. Todavia, as crenças, valores e representações, que orientam as práticas, podem não acompanhar as mudanças. Tendem, dessa forma, a uma resistência (Moscovici, 1978), apontando que simplesmente promulgar a lei não é suficiente para a mudança de comportamento.

Os resultados, que se limitam ao contexto investigado, apontam que existe um cenário difícil para a efetivação dos direitos humanos das mulheres, em especial das que são vítimas de violência. A compreensão dos magistrados sugere uma "cegueira de gênero" (Fontes \& Neves, 1993), que desconsidera a existência de um contexto cultural, que determina às mulheres um papel subalterno, ficando este naturalizado. As mulheres ainda são percebidas como um "segundo sexo" (Beauvoir, 1967), como cidadãs de segunda categoria, restritas a um enquadramento da cultura patriarcal, que impõe vários limites a seu efetivo acesso à cidadania. Talvez por isso, mesmo instrumentalizadas por uma lei específica, as sentenças proferidas pelos magistrados, objeto deste estudo, não contribuem para a construção do direito a uma vida sem violência para as mulheres. Percebe-se que os magistrados não identificam as características de um tipo de violência que atinge as mulheres - violência de gênero - e, assim, não atuam para puni-la ou coibi-la. Percebe-se, a partir deste estudo exploratório e sem pretensão de fazer generalizações, que os magistrados demonstram em suas sentenças que estão pautando suas decisões em suas concepções 
pessoais. As concepções sobre a violência contra as mulheres aparecem ainda associadas a valores e crenças patriarcais.

Não se pretende, dessa forma, defender a pena de privação de liberdade para o agressor. O objetivo deste estudo é fazer pensar na necessidade de se estabelecerem limites para ações que violem a cidadania das mulheres. Observou-se, a partir dos dados estudados, que, apesar das leis, as mulheres continuam sendo tratadas como um segundo gênero, cuja função é manter o vínculo familiar, mesmo que para isso precisem sofrer violência ou até mesmo morrer. Nesse ponto, destaca-se quão necessário se faz estudar a interface entre a psicologia e o direito, de modo a ampliar os conhecimentos e oferecer referências para a atuação profissional no contexto do Poder Judiciário.

\section{Referências}

Alexy, R. (2005) Teoria da argumentação jurídica: a teoria do discurso racional como teoria dajustificação jurídica ( $2^{\mathrm{a}} \mathrm{ed}$.). São Paulo: Landy.

Alves, A. M., \& Coura-Filho, P. (2001). Avaliação das ações de atenção às mulheres sob violência no espaço familiar, atendidas no Centro de Apoio à Mulher (Belo Horizonte) entre 1996 e 1998. Ciência \& Saúde Coletiva, 6 (1), 243-257.

Anchieta, V. C. C., \& Galinkin, A. L. (2005). Policiais civis: representando a violência. Psicologia e Sociedade, 17 (1), $17-28$.

Badin, L. (1997). Análise de conteúdo. Lisboa: Edições 70.

Barsted, L. L., \& Hermann, J. (2001a). Instrumentos internacionais de proteção aos direitos humanos: os direitos das mulheres são direitos humanos. Rio de Janeiro: CEPIA.

Barsted, L. L., \& Hermann, J. (2001 b). As mulheres e os direitos humanos: os direitos das mulheres são direitos humanos. Rio de Janeiro: CEPIA.

Beauvoir, S. (1967). O segundo sexo (2a ed.). São Paulo: Difusão Européia de Livros.

Brandão, E. R. (1998). Violência conjugal e o recurso feminino à polícia. In C. Bruschini \& H. B. Holanda (Orgs.), Horizontes plurais: novos estudos de gênero no Brasil (pp.53-84). São Paulo: Editora 34.

Brasil. Secretaria Especial de Políticas para as Mulheres. (2003). Programa de prevenção, assistência e combate à violência contra a mulher: plano nacional: diálogos sobre violência doméstica e de gênero: construindo políticas públicas. Brasília: Autor.

Brasil. Presidência da República. Secretaria Especial de Políticas para as Mulheres. (2006). Lei Maria da Penha Lein. 11.340 de 7 de agosto de 2006 coíbe a violência doméstica efamiliar contra a mulher. Brasília: Autor.
Costa, J. F. (1989). Ordem médica e norma familiar (3a ed.). Rio de Janeiro: Edições Graal.

Cruz, R. A. (2002). Os crimes sexuais e a prova material. Cadernos Themis Gênero e Direito, 3, 79-100.

Debert, G. G., \& Oliveira, M. B. de. (2007). Os modelos conciliatórios de solução de conflitos e a "violência doméstica". Cadernos Pagu, 29, 305-337.

Diniz, S. G., Silveira, L. P., \& Mirim, L. A. (Orgs.) (2006). Vinte e cinco anos de respostas brasileiras em violência contra a mulher:alcances elimites (pp.266-287). São Paulo: Coletivo Feminista Sexualidade e Saúde.

D'Oliveira, A. F., \& Schraiber, L. B. (2000). Violência doméstica como problema para a saúde pública: capacitação dos profissionais e estabelecimento de redes intersetoriais de reconhecimento, acolhimento e resposta ao problema. Anais do Congresso Brasileiro de Saúde Coletiva [CD-Rom]. Salvador, Bahia.

Fontes, A. \& Neves, M. G. (1993). Gestão municipal e perspectiva de gênero. Revista de Administração Municipal, 206, 52-63.

Giffin, K. (1994). Violência de gênero, sexualidade e saúde. Cadernos de Saúde Pública, 10 (Supl. 1), 146-155.

Guimarães, F., Silva, E. C., \& Maciel, S. A. B. (2007). "Mas Ele diz que me ama...": cegueira relacional e violência conjugal. Psicologia: Teoria e Pesquisa, 23 (4), 481-482.

Heise, L., Pitanguy, J., Germain, A. (1994). Violencia contra la mujer: carga de salud oculta [mimeo]. Manuscript published as: violence against women: the hidden health burden. Washington, D.C.: The international Bank for Reconstruction and Development/The World Bank.

Meneghel, S. N., Barbiani, R., Steffen, H., Wunder, A. P., Dalla Roza, M., Rotermund, J., et al. (2003). Grupos de mulheres em situação de vulnerabilidade de gênero. Cadernos de Saúde Pública, 19 (4), 955-963.

Mirim, L. A. (2006). Balanço do enfrentamento da violência contra a mulher na perspectiva da saúde mental. In S. G. Diniz, L. P. Silveira \& L. A. Mirim (Orgs.), Vinte e cinco anos de respostas brasileiras em violência contra a mulher: alcances e limites (pp.266-287). São Paulo: Coletivo Feminista Sexualidade e Saúde.

Moscovici, S. (1978). A representação social da psicanálise. Rio de Janeiro: Zahar.

Nascimento-Schulze, C. M., \& Camargo, B. V. (2000). Psicologia social, representações sociais e métodos. Temas em Psicologia da SBP, 8 (3), 287-299.

Oliveira, J. M., \& Amâncio, L. (2006). Teorias feministas e representações sociais: desafios dos conhecimentos situados para a psicologia social. Estudos Feministas, 14 (3), 597-615

Pinto, C. R. J. (2003). Uma história do feminismo no Brasil. São Paulo: Fundação Perseu Abramo.

Portella, A. P. (2000). Abordagem social sobre a violência e saúde das mulheres. Jornal da Redesaúde, 22, 17-19.

Porto, M. S. G. (2006). Crenças, valores e representações sociais da violência. Sociologias, 16, 250-273. 
Porto, M., Santos, M. L. G., \& Leite, M. F. A. (2008). Os crimes contra as mulheres e a perícia psicológica no contexto da Lei Maria da Penha (Lei no. 11.340/2006). In F. P. Costa (Org.), Lei Maria da Penha: aplicação e eficácia no combate à violência de gênero (pp.58-68). Rio Branco: Edufac.

Sabadell, A. L. (2005). Manual de sociologiajurídica: introdução a uma leitura externa do direito (3a ed.). São Paulo: Revista dos Tribunais.

Saffioti, H. L. B. (2004). Gênero, patriarcado, violência. São Paulo: Fundação Perseu Abramo.

Schraiber, L. B., d'Oliveira, A. F. L. P., Strake, S. S., \& Liberman, M. D. (s.d.). Violência contra a mulher políticas de saúde no Brasil: o que podem fazer os serviços de saúde? Manuscrito não-publicado, Departamento de Medicina Preventiva, Universidade de São Paulo.

Scott, J. (1990). Gênero: uma categoria útil de análise histórica. Educação e Realidade, 16 (2), 5-22.
Silva, M. D. (1999). Violência doméstica e sexual: o invisível e o indizível nas relações de gênero. In M. Ferreira (Org.), Mulher, gênero e políticas públicas (pp.11-118). São Luiz: UFMA.

Soares, B. M. (2005). Enfrentando a violência contra a mulher: orientações práticas para profissionais e voluntários(as). Brasília: Secretaria Especial de Política para as Mulheres.

Streck, L. L. (2002). Os crimes sexuais e o papel da mulher no contexto da crise do Direito: uma abordagem hermenêutica. Cadernos Themis Gênero e Direito, 3, 135-164.

Venturi, G., Recamán, M., \& Oliveira, S. (Org.) (2004). A mulher brasileira nos espaços públicos e privados. São Paulo: Fundação Perseu Abramo.

Recebido em: 21/5/2009

Versão final reapresentada em: 19/7/2010

Aprovado em: 18/8/2010 
